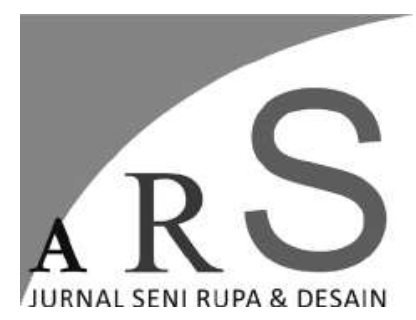

Volume 22 Nomor 1 - April 2019

\section{THE CONCEPT OF “THE SYNERGY OF INDONESIA RATTAN” AT THE INTERIOR DESIGN OF NATIONAL RATTAN INNOVATION CENTER (PIRNas) BY USING DESIGN THINKING METHOD}

\author{
Zulyo Kumara Pratama Putra \\ E-mail: zulyokumarapratama@gmail.com
}

Kata kunci: rotan, PIRNas, identitas, The Synergy of Indonesia Rattan, metode design thinking

\begin{abstract}
In order to support the development of national rattan industry through appropriate innovation, in 2012 the government established the Indonesia Rattan Innovation Center (PIRNas) based in Palu, Central Sulawesi. As an institution that hold important roles in rattan industry development, there's still has some basic problems in interior sector that should be solved. The method in designing the interior of PIRNas is used design thinking (Bob Gill 2004). The result of PIRNas design plan will be focused in strengthening "The Synergy of Indonesia Rattan" concept and story that was being adapted by on attention and appreciation toward values of rattan, especially the history, process, and rattan national potency. For the application itself, designer applied rattan material with all room elements that complete each other and continuous. In the end, this application is expected to presenting the strong perception of Indonesia Rattan Innovation Center's roles and identity as rattan national research and development institution.
\end{abstract}

Keywords: rattan, PIRNas, Identity, the Synergy of Indonesia Rattan, design thinking method 


\section{Introduction}

Indonesia has a lot of natural resources. One of Indonesian potential resources is rattan material. Indonesia becomes the largest producer of rattan commodity and its potential dominates the world rattan market. As the largest rattan producer, Indonesia has contributed $80 \%$ of the world rattan needs. $90 \%$ of rattan is produced from natural forests in Sumatra, Kalimantan, Sulawesi, and around $10 \%$ is produced from rattan cultivation. (Grace, 2012)

Responding to this issue, to support the national rattan industry development through appropriate innovations, the government established the National Rattan Innovation Center (PIRNas, 2015) in Palu, Central Sulawesi in 2012. PIRNas or National Rattan Innovation Center is a research and development institution for rattan under the Ministry of Industry of the Republic of Indonesia. PIRNas has a vision, mission and program related to the development of innovation and national rattan potential, from both natural and human resources. However as an important institution in the rattan development industry in Indonesia, there are a number of fundamental problems related to the interior design at PIRNas that must be fixed. These problems include the lack of interior design focus, the lack of space standardization and facilities supporting in the center for rattan material innovation and the lack of harmony between interior design applied in the PIRNas and the vision, mission and program of PIRNas cause the purpose of PIRNas as a place representing rattan as an Indonesian icon hasn't been achieved maximally.

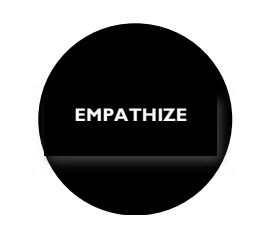

INITIAL DESIGN PROCESS

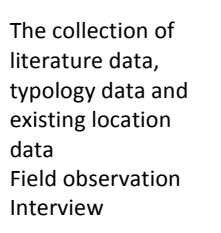

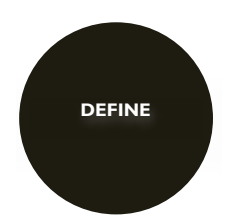

ANALYSIS PROCESS

Data compilation
Data analysis and Data analysis and programing

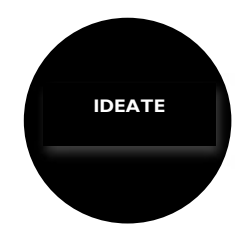

IDEA FINDING PROCESS

Compilation of

design concepts

Schematic design and alternative idea

Schematic design evaluation Design development Final design
The problems mentioned above must be solved by space redesigning in order to fulfill the activity needs and facilities for both visitors and stakeholders and enable becoming information source and documentation covering the functions of study, exhibition, education, administration, and information. The issue becomes the background for choosing the interior of the National Rattan Innovation Center (PIRNas) as the object of this Final Project design.

\section{Design Method}

The design method used in this design process is the design thinking method. According to Gill (2004) a creative approach by collecting existing information and opportunities to be synthesized into innovation and work ideas. This design method consists of 5 steps:

The design process covers several steps based on the design thinking framework (Figure 1) and activities done by the designer at the steps. The steps are:

\section{Empathize}

The first step is to understand the existing problems at PIRNas building as the basis of the design background, by recognizing objects, collecting data by conducting direct observations on objects, seeking information and conducting interviews with the stakeholder and collecting supporting data to design, including the activities. 2. Define

It is the process of determining or focusing on the objectives. The collected data is selected so the author gets reliable and valid data upon

Figure 1. Design Thinking Framework (Source: Bob Gill, 2004) 


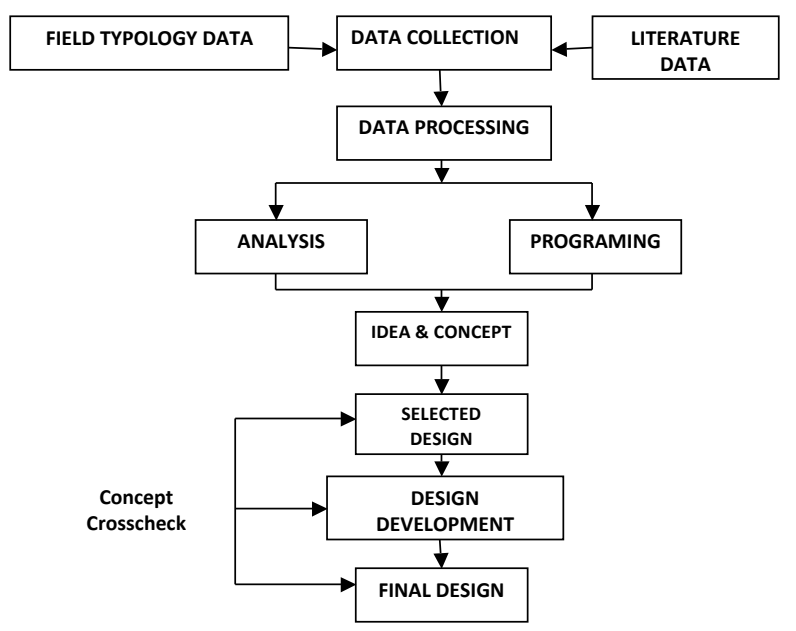

the design goals. Data collection is grouped into several parts, by conducting literature studies, typology data collection, and document analysis.

3. Ideate

It is the process of finding and focusing design ideas and the way to solve problems or find the solutions. Brainstorming is done at this step.

\section{Prototype}

The step of making model. The model will be tested for its suitability based on concepts, objectives, and solutions so it can be known whether the design has succeeded in answering or solving the problems.

\section{Test}

The step is carried out as a form of design criticism covering input from other people, and design evaluation.

\section{Results}

\section{Design Problem}

"How to design the interior of the National Rattan Innovation Center (PIRNas) presenting a strong image identity and its role as a center for national rattan research and development institutions".

\section{Design Concept}

Broadly speaking, the chosen concept answering the PIRNas interior design problem is the concept of "The Synergy of Indonesia Rattan", based on the great attention and appreciation to the rattan travel values, especially its history, process, and potential in Indonesia. The concept refers to the meaning of synergy, unity and integration in the national rattan industry and refers to the objectives / aspects focusing on design in relation to the maximization of basic ideas from the vision, mission and PIRNas program as a bridge between various rattan industry sectors from upstream to downstream. The purpose and focus of the intended design reflects the efforts to harmonize the synergy from national rattan industry various sectors / segments and to represent the spirit / hope for the return of Indonesian rattan in its heyday.

\section{Discussion}

Aspects becoming the selection basis of design concepts, are:

\section{Rattan Travel Values}

Rattan is a local material having long history and is entirely in the Indonesian hands. The elements of rattan travel values are implemented into a theme. The applied theme is a story adapting the history, process, and segmentation of the national rattan industry, as well as the PIRNas program scheme into the interior. The theme is expected to be able to strengthen the image representing the identity and role of the PIRNas as a center for research and development of rattan material.

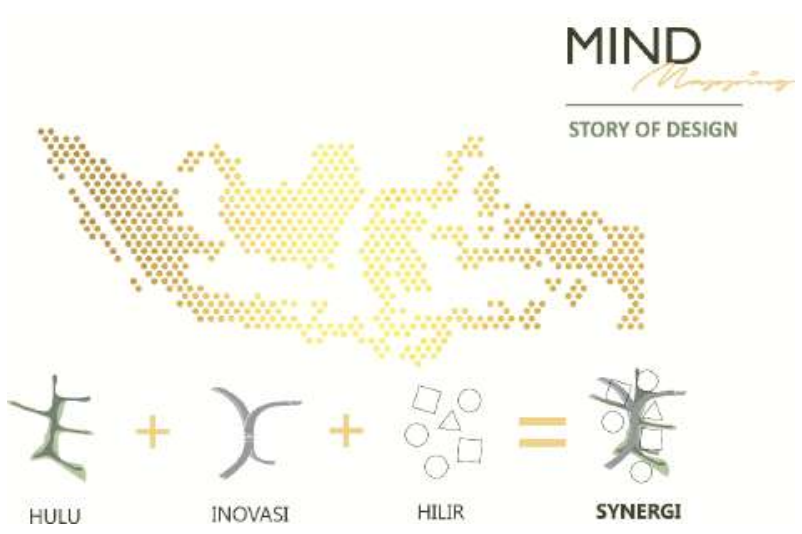

Figure 3. Aspects becoming the Basis of the Design Concept Selection

(Source: Analysis Result, 2017)

The designer will apply the national rattan industry scheme as a concept of grouping space design zones. It is to harmonize the synergy upon various sectors, the zoning group space management dividing into several groups Upstream Sector (cultivation place and standard development), Development Sector (a place becoming the rattan material development, such 
as innovation, and design, and Downstream Sector (finished goods or marketing).

\section{Image, Identity, and Role}

An innovation center is frequently associated with new or up-to-date ideas having expressive, explorative, and imaginative nuances. Therefore, the chosen style answering the problem and the need is "Contemporary Design" style. The style application is implied in the designed elements from the form / appearance, material process, facilities, and applied technology.

To present the PIRNas interior having expressive, explorative, and imaginative nuances so the rattan material exploration is combined with other materials into interior elements and interior supporting elements. The combination of all rattan material elements complement each other continuously. It is expected to produce a balanced composition, to give different rattan nuances, and to bring new space experience.

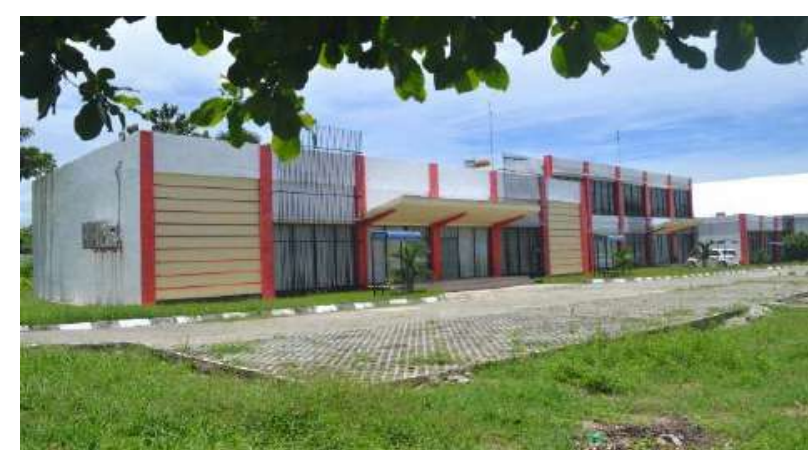

Figure 4. PIRNas building (Source: Zulyo's Documentation, 2017)

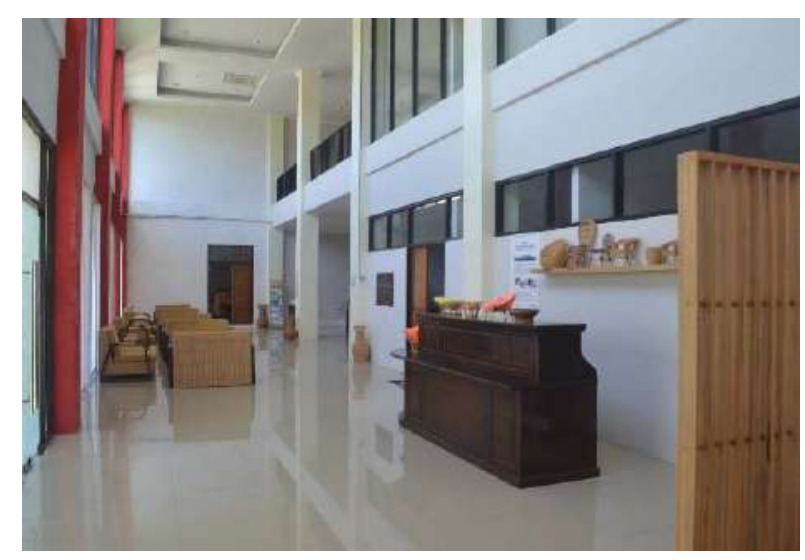

Figure 6. Lobby Area

(Source: Zulyo's Documentation, 2017)

\section{PIRNas Vision, Mission and Program}

PIRNas is a new forum for conducting research, bridging among various sectors in rattan industry from upstream to downstream such as producers, farmers, craftsmen, industry players, designers, design experts, and researchers to build synergies among stakeholders to interact each other, to learn from each other, and to work together.

The main aspect concerning the design is creating a research institution, not only accommodating the research and development needs of rattan material, but also becoming an interactive, attractive, and representative education and recreation place. Based on the planned concepts, PIRNas has educational and recreational facilities / functions including training and research facilities, exhibition rooms, operational facilities, and other supporting facilities.

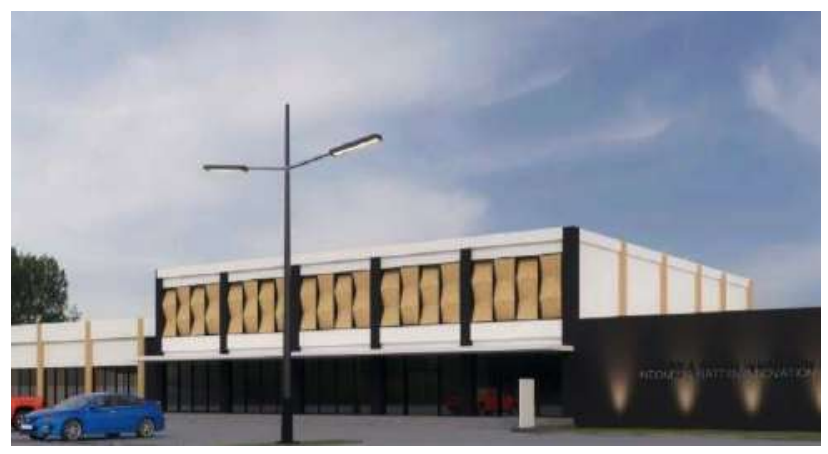

Figure 5. PIRNas building (Source: Design Result, 2017)

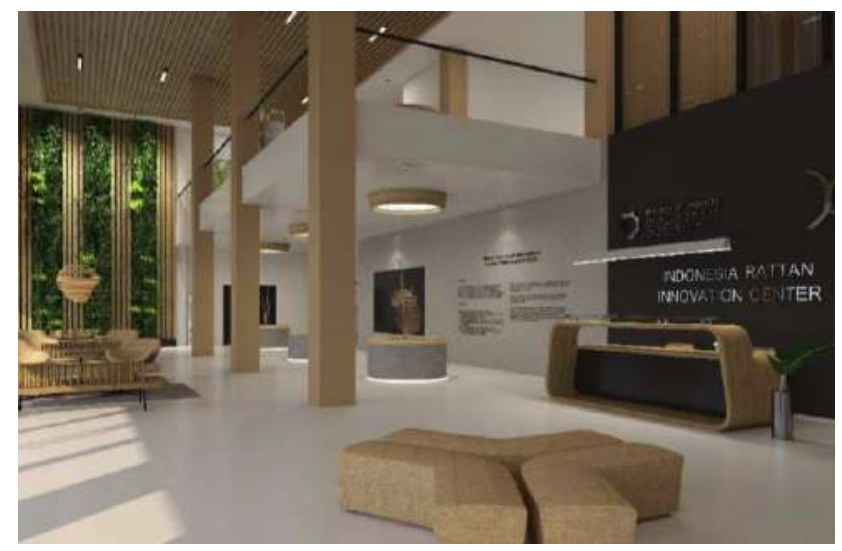

Figure 7. Lobby Area Perspective (Source: Design Result, 2017) 
The final design of the concept application is as follows:

\section{a. Lobby}

Lobby room is designed adjusting to the needs by adding the area and dividing the lobby into areas giving ease for users to move. These areas include the reception area, audiovisual area, lounge area, material display area, and supporting facilities including prayer rooms, toilets, and control rooms. The application of audiovisual facilities and material displays is intended as an educational medium allowing visitors / guests to obtain data, information related to history, the scheme of rattan industry travel, development, potential and rattan processing in Indonesia. In addition, the facility availability is intended to give a first impression representing the character of the PIRNas and to support the upstream segmented theme / story in the lobby room.

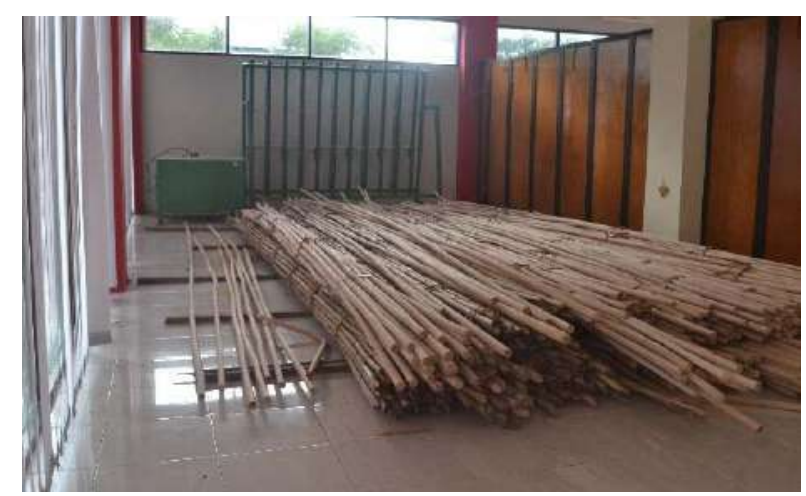

Figure 8. Classroom

(Source: Zulyo's Documentation, 2017)

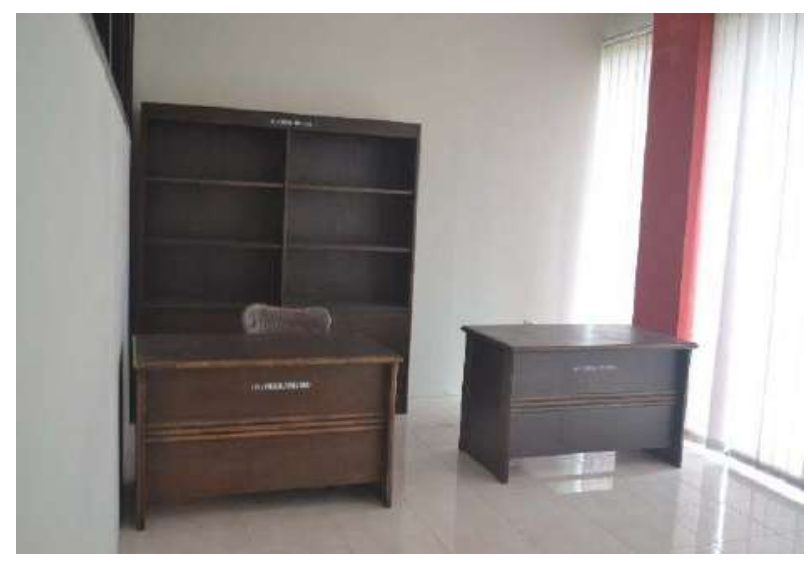

Figure 10. Meeting Room

(Source: Zulyo's Documentation, 2017) b. Classroom / Training Center

After going through the lobby, visitors are directed to the training room. It covers a meeting room used for various activities, such as study rooms, meeting rooms, training rooms, seminar rooms or other program activities. The space concept applied is a moveable concept. It sometimes is inefficient because it is not frequently used. The room function can be changed to another room such as a discussion room and meeting room. The area uses audience seating that can be arranged in individual rows or in group tables.

c. Office

To realize the target space concept of processing PIRNas, there are several main focus components such as: widening area and spatial planning, providing the best office equipment by considering the function of each room, and selecting individual working stations for the more private work and separating based on the function implementation of each section.

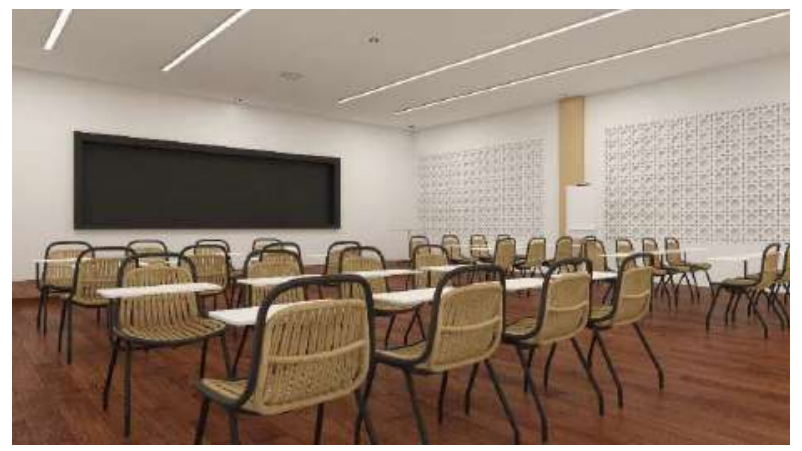

Figure 9. Classroom/Education and Training Perspective Source: Design Result, 2017

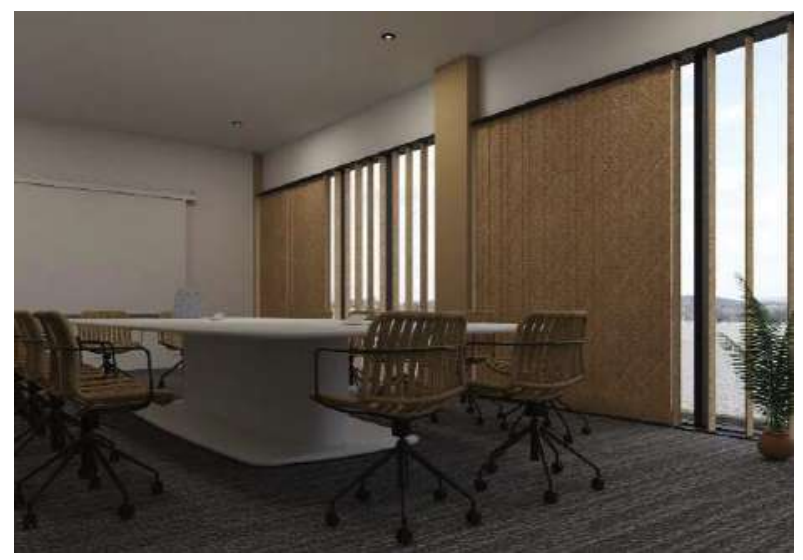

Figure 11. Meeting Room Perspective

(Source: Design Result, 2017) 


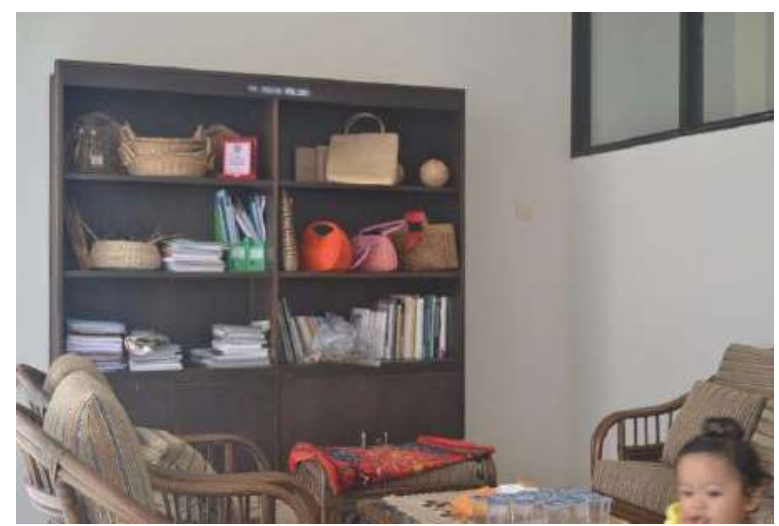

Figure 12. The Head Room

(Source: Zulyo's Documentation, 2017)

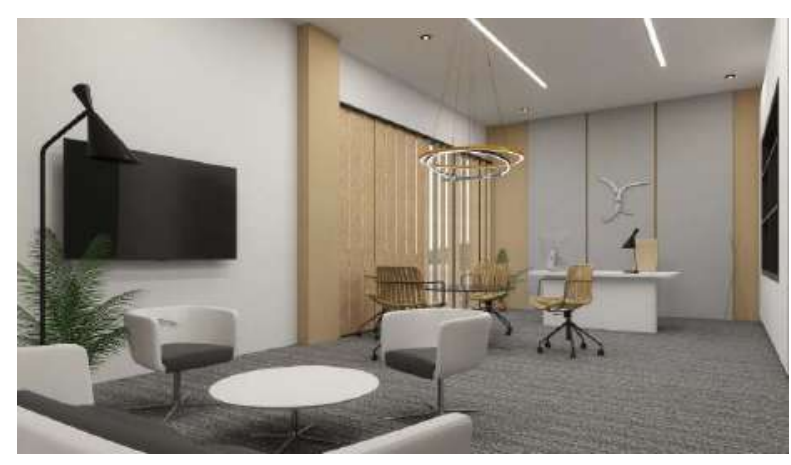

Figure 13. The Head Room Perspective

(Source: Design Result, 2017)

\section{d. 2nd Floor Hall}

In the 2nd floor hall area, the theme and story applied is the development sector or as a meeting area between the upstream and downstream sectors. The second floor hall is designed to divide into areas providing information related to various rattan material innovations and PIRNas role both as a research and development institution. The area includes rattan connection type display area, rattan material display area, study area, model display area, and corner book.

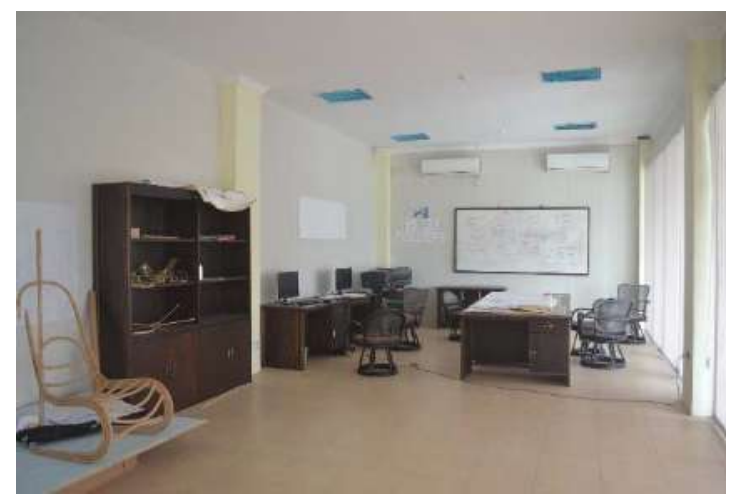

Figure 16. Design Room

(Source: Zulyo's Documentation, 2017)

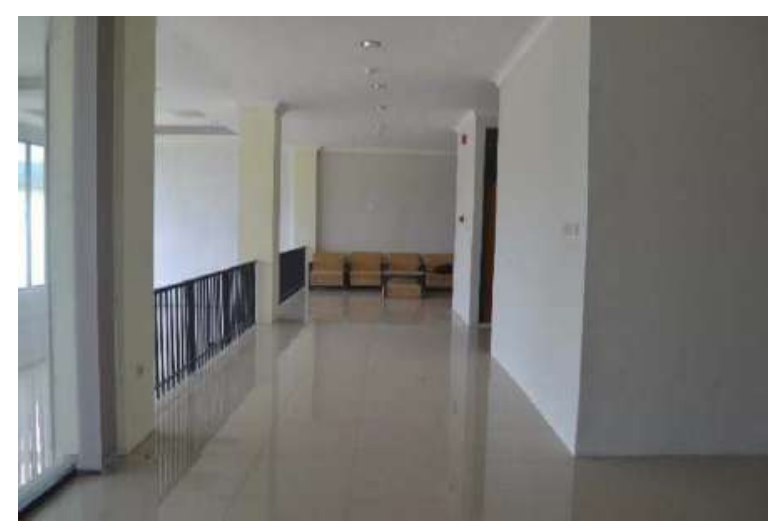

Figure 14. 2nd Floor Hall

(Source: Zulyo's Documentation, 2017)

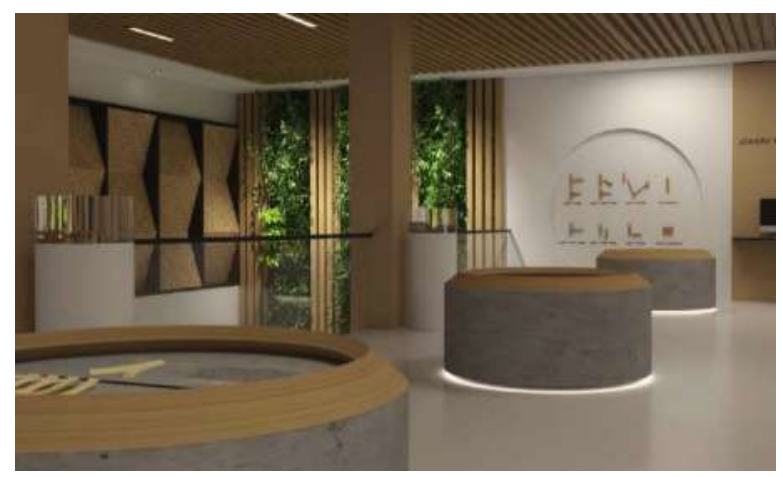

Figure 15. $2^{\text {nd }}$ Floor Hall

(Source: Design Result, 2017)

\section{e. Design Room}

To realize the activity objectives in designing the PIRNas space, there are several covered aspects including: The application of casual modern flexible open space studio concept will make the users comfortable, relaxed, unfettered, and productive. It also provides a place for designers / users to invent ideas, aspirations, and feelings, to express their creativity, to support designers thinking beyond conventional boundaries and to observe understanding the designs made by the designers.

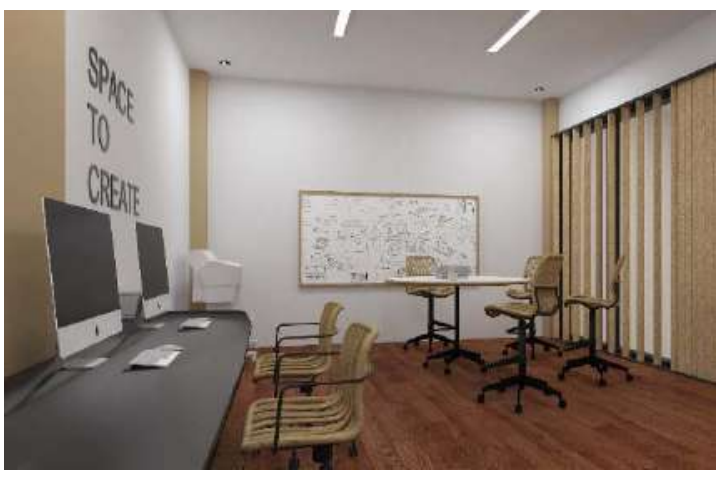

Figure 17. Design Room Perspective (Source: Design Result, 2017) 


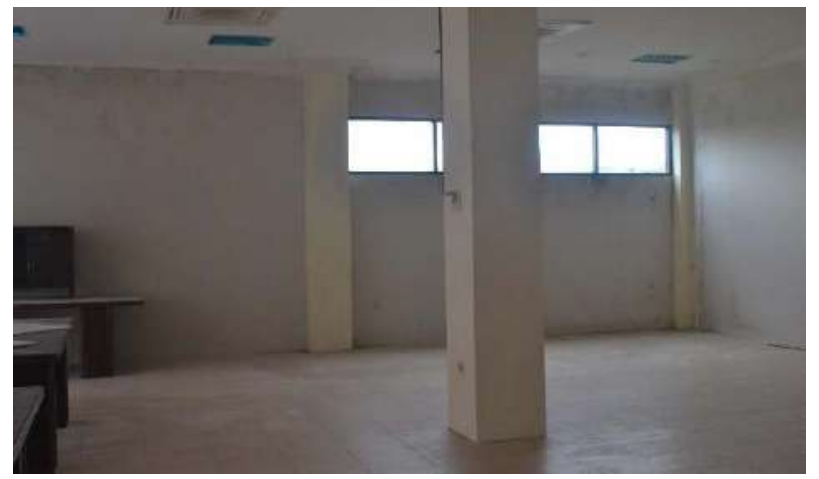

Figure 18. Material Test Laboratory Room (Source: Zulyo's Documentation, 2017)

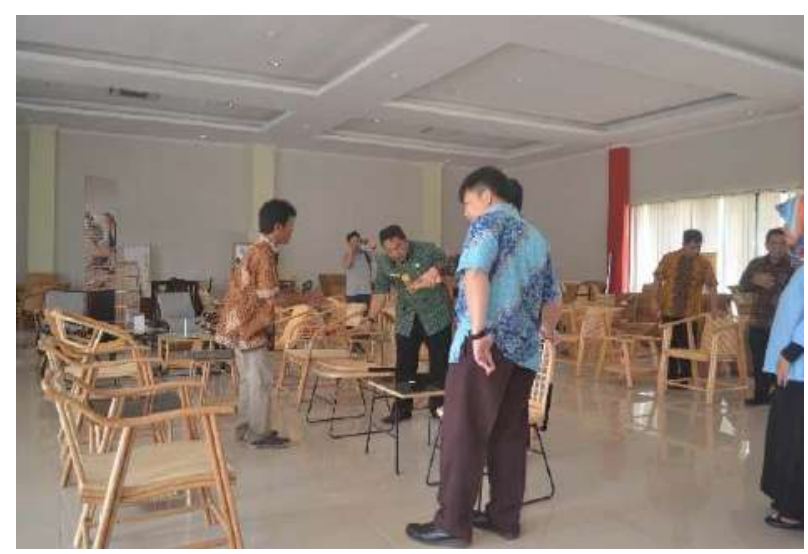

Figure 20. Rattan Products at PIRNas Building (Source: Zulyo's Documentation, 2017)

\section{g. Display Room}

The applied theme in the display room is the story of the downstream sector. The concept application is the technological innovation displaying works. Users are given a new convenient interesting experience. The area is equipped with the latest technology. one of them is the application of supporting facilities such as displaying works, forming and directing circulation.

\section{Conclusion}

National Rattan Innovation Center Interior Design (PIRNas) in Palu uses the design thinking method (Gill, 2004) providing optimal result. Based on the design method used, the solution is obtained from the PIRNas interior design by using the design concept "The Synergy of Indonesia Rattan" packaged in "Contemporary Design" style.

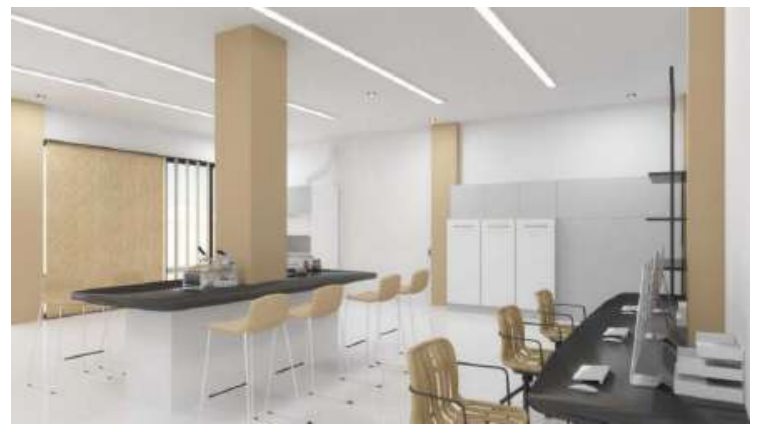

Figure 19. Material Test Laboratory Room Perspective (Source: Design Result, 2017)

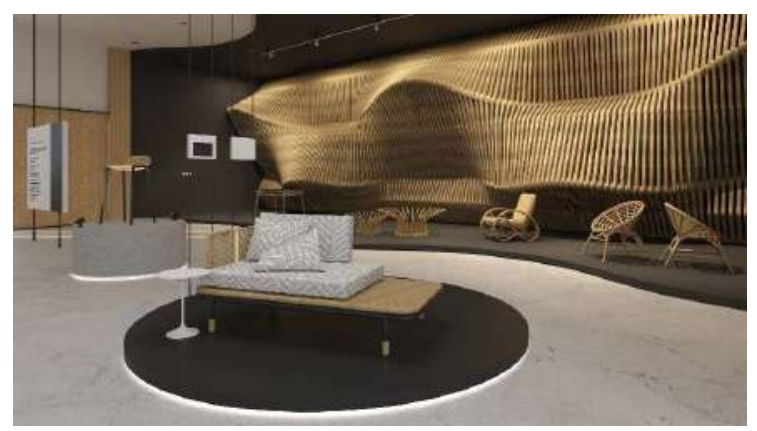

Figure 21. Rattan Products in Display Room at PIRNas Building

(Source: Private Documentation, 2017)

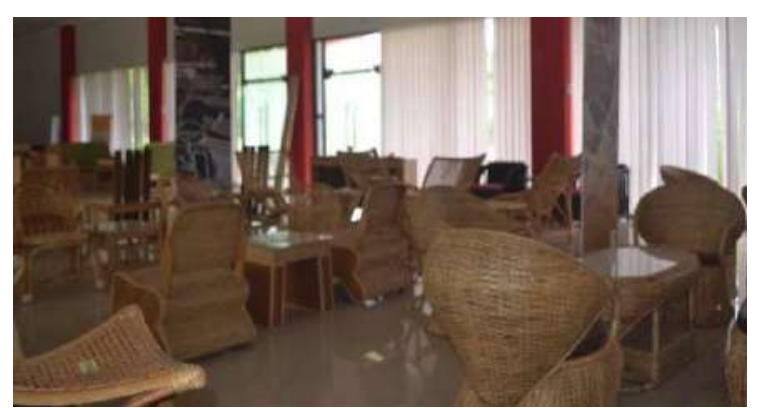

Figure 22. Rattan Chairs and Tables exhibited at PIRNas Building

(Source: Zulyo's Documentation, 2017)

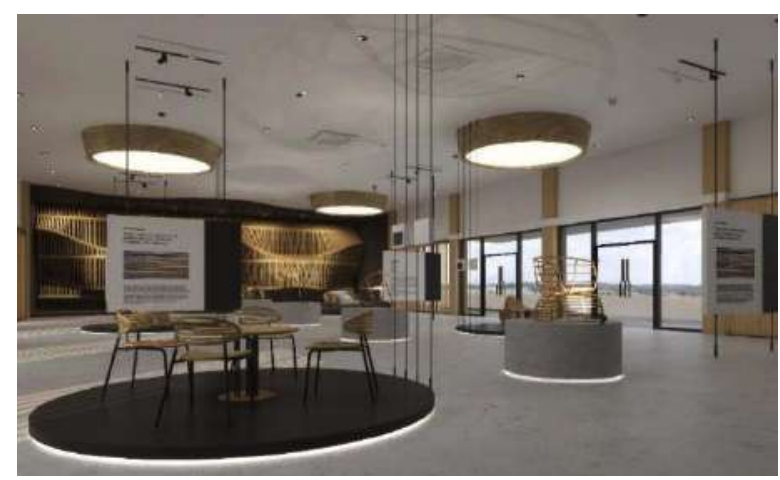

Figure 23. Display Room View at PIRNas building (Source: Private Documentation, 2017) 
The concept is adapted from big, attention and appreciation of the rattan travel values, mainly its history, process and national rattan potential in Indonesia. This concept refers to the meaning of synergy, unity and integration in the national rattan industry and refers to the objectives / aspects focusing on design relating to the maximization of basic ideas from the vision, mission, and PIRNas program as a bridge among various rattan industry sectors from upstream to downstream. The purpose and focus of the intended design reflects the efforts to harmonize the synergy of various sectors / segments of the national rattan industry, as well as efforts to represent the form of spirit / hope for the return of Indonesian rattan heyday.

While the "Contemporary Design" style is chosen because the style is in accordance with the characteristics of an innovation center associating to new or up to date things. This style will present a flexible and innovative design, both form and appearance, material type, material processing, and technology. It is expected the design result will be able to answer the problem by applying the appropriate concept, and representing the identity / role of the PIRNas as a center for national rattan research and development institution.

\section{Bibliography}

Devo, P. (2012). Perancangan Interior Creative Collaborative Space di Surabaya. Universitas Kristen Petra.

Gill, B. (2004). Graphic Design as a Second Language. Australia: Images Publishing Group Pty Ltd.

Grace, H. (2012). Perkembangan Material Rotan dan Penggunaan di Dunia Desain Interior. Universitas Bina Nusantara. Jakarta. PIRNas. (2015). Catalogue of PIRNas 2015. Palu. 